\title{
Three-dimensional reconstruction of a masonry building through electrical and seismic tomography validated by biological analyses
}

\author{
Ettore Cardarelli ${ }^{1}$, Giorgio De Donno ${ }^{1 *}$, Ilaria Oliveti ${ }^{1}$, Claudia Scatigno ${ }^{2,3}$ \\ 1 "Sapienza" University of Rome - DICEA Via Eudossiana, 18, 00184 Rome, Italy \\ 2 "Sapienza” University of Rome - DST Piazzale Aldo Moro 5, 00185 Rome, Italy \\ ${ }^{3}$ University of the Basque Country, (UPV/EHU), Department of Analytical Chemistry Barrio Sarriena s/n, 48940 Leioa, Spain
}

Received October 2016, revision accepted August 2017

\begin{abstract}
In this paper, we present an integrated approach, for assessing the condition of an ancient Roman building, affected by rising damp and cracking phenomena. The combination of high-resolution geophysical methods, such as seismic and electrical tomography, with biological information, allowed a more detailed evaluation of the state of conservation of the masonry building. A preliminary three-dimensional electrical survey was conducted to detect the existing building foundations and to determine the variation of the resistivity in the ground. Then, electrical and seismic tomography investigations were carried out on an inner wall of opus caementicium, subjected to rising damp effects and cracks. This approach was adopted to obtain a high-resolution image of the wall, which allowed to identify the inner mortar and the outer brick component from resistivity and velocity contrasts. Furthermore, the geophysical results revealed evidence of wall fractures (indicated by low velocity and high resistivity values) and a significant volume where rising of damp was taking place (resulting in a low resistivity zone). Biological analyses validated the geophysical model: in fact, the biological proliferation occurred up to a height of $0.75 \mathrm{~m}$, where the interface between high and low resistivity values was recovered. This approach can be employed to reconstruct a three-dimensional model of masonry structures in order to plan recovery actions.
\end{abstract}

\section{INTRODUCTION}

Understanding the inner geometry, the constructive materials and the degree of conservation of ancient buildings are pivotal issues when cultural heritage undergoes degradation processes due to the ravages of time, human interventions, or natural phenomena. In this sense, the application of non-destructive geophysical testing can be an important tool for assessing the current state of an archaeological structure. Geophysical methods were applied worldwide during the last decades for archaeological prospecting in order to detect and non-invasively characterise ancient structures without any damage (Gaffney 2008).

Ground penetrating radar (GPR) has been the most employed technique amongst the geophysical surveys for archaeological targets (Goodman and Piro 2013). Through this method, a detailed image of the existent structures or important information about the location of buried bodies can be retrieved (Conyers 2013). Some successful applications concerned the detection and characterisation of ancient structures (e.g., Orlando and Slob

*giorgio.dedonno@uniroma1.it
2009; Cataldo et al. 2012), the location of cavities and hidden objects in the shallow subsurface (e.g., Neubauer et al. 2002; Piro, Goodman and Nishimura 2003), the recognition of individual anomalous zones within ancient buildings, and the evaluation of the current state of structures (e.g., Perez-Gracia et al. 2013; Orlando et al. 2015). Although being a high-resolution technique, the GPR signal has the disadvantage of a lower depth of penetration in cases of conductive media (Daniels 2009).

An estimation of the elastic parametres at low strain of the structural elements can be achieved by seismic tomography, where the low velocity zones are straightforward indicators of material weakness. Some studies have been focused on the cracking-prone zones (e.g., Cardarelli and De Nardis 2001) or on the investigation of the foundation structure and ground materials of ancient buildings (e.g., Polymenakos et al. 2005).

In this sense, electrical resistivity tomography (ERT) can provide useful information about the hidden foundations and the surrounding geology and, as long as non-invasive electrodes are used, also about the structural elements. This technique was used on stone exposures (Sass 2005) in an effort to understand the processes of 
(a)

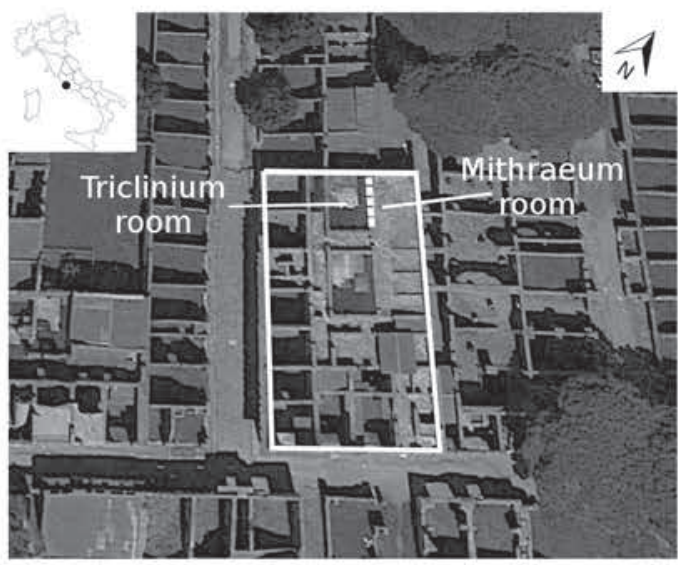

(c) (b)

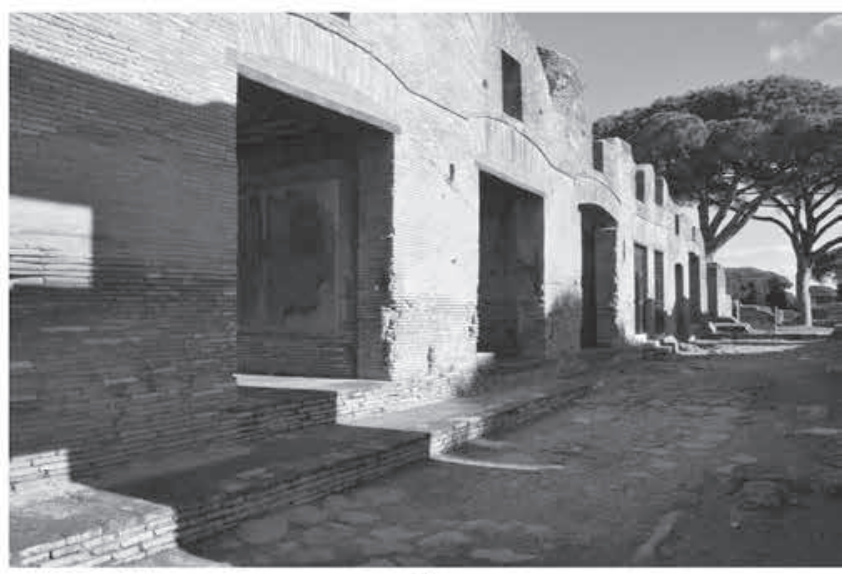

(d)

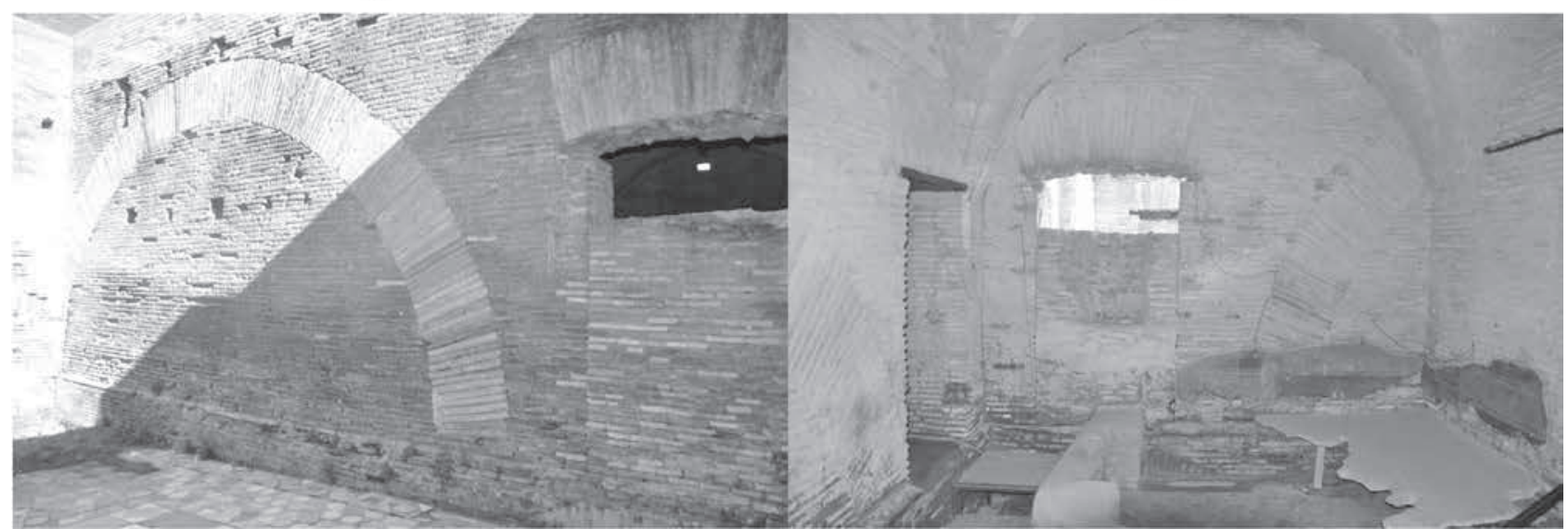

Figure 1 (a) Casa di Diana at the Ostia Antica archaeological site (indicated with a white rectangle) and location of the Triclinium wall (dashed line); (b) street view (Via di Diana); (c) outer face of the Triclinium wall located in the Triclinium room; (d) inner face of the Triclinium wall located in the Mithraeum room.

stone weathering, for analysing the rising damp phenomenon and assessing the moisture content of historic walls (Mol and Preston 2010), and to study a masonry wall (Tsourlos and Tsokas 2011).

Since it is not always possible to rate a single geophysical method as best suited for the particular problem at hand, the integration of different techniques can remove ambiguities on interpretation of geophysical models and increase the degree of accuracy of the physical parametres (Tsokas et al. 2013; Cardarelli et al. 2014). However, other methods concerning chemistry, geomatics, geotechnical, or hydraulic engineering can help to unravel the complexity of many archaeological sites where different materials could give a similar geophysical response. Integrated approaches have been applied for archaeological prospection (e.g., Merello et al. 2013), pertaining to geomatics and geophysics (e.g., D'Aranno et al. 2016), geotechnical engineering and geophysics (e.g., Soupios, Loupasakis and Vallianatos 2008; Westley, Plets and Quinn 2014), or geochemistry and geophysics, in order to study ancients buildings affected by rising damp and cracking phenomena (e.g., Cardarelli et al. 2016b).
Rising damp is one of the main causes of decay to historical masonry materials, and it is surely the most widespread phenomenon leading to moisture presence in building structures (Franzoni 2014). Moisture plays a key role in the degradation of porous materials, being directly or indirectly responsible for several decay processes (Gentilini et al. 2012; Mustafa 2013). Degradation processes, such as corrosion and biological growth, can arise or be intensified in the presence of rising damp. In fact, the hydraulic flow induced by the biological system from the shallow aquifer through capillary transport can speed up the deterioration of building materials.

In this sense, different approaches have been adopted to isolate and identify the different biological organisms. For example, indices of taxonomic or phylogenetic diversity aim to quantify the microbial diversity, even though they require the evaluation of the non-equivalence of ranks and the representatives of the detected taxa (Green, Bohannan and Whitaker 2008; Creer et al. 2016; Singh, Singh and Prabha 2016). Furthermore, a correct identification of the species is important to classify the damage 
occurring within a structure. Additionally, it is necessary to adopt an appropriate method for assessing the biological evolution, driven by the processes of proliferation and competition.

In this regard, the integrated approach presented in this work encompasses the use of electrical and seismic tomography investigations validated by biological analyses, aiming to assess the state of conservation of an ancient Roman building located in the Ostia Antica archaeological site (Rome, Italy), affected by rising damp on parietal walls and cracking in load-bearing walls. The experimental procedure has been divided into five main steps:

(i) establishing the hydro-geological setting through twodimensional (2D) ERT investigations;

(ii) detecting building foundations using three-dimensional (3D) ERT with customised arrays;

(iii) understanding the source of rising damp affecting the investigated wall, merging together results obtained at points (i) and (ii);

(iv) assessing the state of conservation of the wall with a combined use of 3D ERT and seismic tomography investigations;

(v) validating results by biological analyses.

Owing to the above consideration, GPR technique was discarded because the masonry wall was expected to be electrically conductive due to the rising damp. In addition to this, since the depth of penetration is inversely proportional to the radiated frequency, GPR would not have been able to detect the deep foundations.

\section{Material and methods}

\section{Site description}

The investigated building, named "Casa di Diana", located at a distance of $3 \mathrm{~km}$ from the Tyrrhenian sea, $250 \mathrm{~m}$ from the Tiber River, and $4 \mathrm{~km}$ from the Fiumicino International airport, was built in the central area of Ostia Antica (Rome, Italy) around $130 \mathrm{CE}$ (Figure 1a). The building is a $40 \mathrm{~m} \times 22 \mathrm{~m}$ rectangular masonry structure with $60-\mathrm{cm}$ wide load-bearing walls and two main corridors. The house originally had five floors, with shops at the ground floor and apartments at the upper levels: nowadays, only the ground floor still survives (Figure 1b). In the past, the house used to have an advanced hydraulic system, in which the inner fountain, supplied by lead pipes from the street to the courtyard, stands out as an example of aristocratic luxury adapted to the architecture of an insula. An inner well, having a depth of $4.20 \mathrm{~m}$, and an external tank, adjacent to the building, are still open for inspection.

One of the most important rooms is the so called Mithraeum, representing a sanctuary consecrated to the Indo-European god Mithra, whose cult increased in the first century CE. This room was constructed with a central aisle flanked on each side by raised seats (podia), located at a height of $50 \mathrm{~cm}$ above the floor (Clauss 2001).

The house is mainly composed of bricks and pozzolanic mortar combined through the opus caementicium technique (inner mortar and two outer brick layers). The masonry surfaces exhibit exfoliation, delamination, cracking, chipping, and biological proliferation as an effect of the degradation process ongoing at the study site. A whitish patina is clearly visible on masonry surfaces.

In a previous work, Cardarelli et al. (2016b) established the hydro-geological setting of the archaeological site (point (i) of the proposed procedure) in order to assess the causes of the rising damp in masonry building materials. Through 2D geo-electrical investigations, they detected a freshwater aquifer at a depth of $2.5 \mathrm{~m}$ ( $0 \mathrm{~m}$ a.s.1.), within the sand deposits, whereas salt water was found at a depth of $8 \mathrm{~m}(-5.5 \mathrm{~m}$ a.s.1.). The depth of the salt water/fresh water interface is comparable to that recovered by Mikhalova et al. (1999). Thanks to geo-chemical analyses, they identified that the shallow water probably comes from the Malafede basin with a slight salt contribution due to salt deposits or to the interaction with the deeper saline water.

In this work, geophysical investigations have focused on the analysis of one of the perimetral wall of the Triclinium room, adjacent to the Mithraeum (Figures 1c,d). This wall (named in the following sections as Triclinium wall) is $8.3 \mathrm{~m}$ wide, $1.8 \mathrm{~m}$ high, and $0.7 \mathrm{~m}$ deep and is embedded within a pre-existent arch. The wall is seriously damaged as confirmed by efflorescences and fractures directly visible on its surface. Overall, the Mithraeum room is undergoing a noteworthy degradation process (Scatigno $e t$ al. 2016a,b), particularly on the Mithraeum face of the Triclinium wall. Here, the consumption of mortar joints, more permeable than bricks, is evident, as well as a typical morphology of degradation by biological growth. The biological proliferation can induce aesthetic damage on surfaces (vegetative structures, coloured patches through biogenic pigments, or patinas and crusts) but, more importantly, a decay of the mechanical properties of the construction materials (Crispim and Gaylarde 2005).

\section{Geophysical investigations}

We performed a 3D ERT survey for detection of the foundations, while 3D ERT and two seismic tomography lines were acquired on the Triclinium wall (Figures 2 and 3).

\section{Foundation}

A 3D ERT array was applied both outside, along three sides of the building (Figure 2a), and inside (alongside the corridors) using a 48-channel IRIS Instruments SyscalPro, with a dipoledipole configuration working on a combination of two different arrays ( $M$ shaped and U shaped in Figure 2a). The in-line measurements (current and potential electrodes on the same branch of the array) were executed using a maximum value for the dipole separation $a$ equal to 5 , whereas the maximum dipole separation factor $n$ is 6 . The cross-line measurements (current injected on a certain branch of the array and potential measured on the others) were performed using a maximum dipole separation $a$ of 7 . Globally, we acquired 2512 apparent resistivity measurements. Stainless steel rods (diametre $=1 \mathrm{~cm}$, Figure $3 \mathrm{a}$ ) and square copper plates (length $=10 \mathrm{~cm}$, Figure $3 \mathrm{~b}$ ) were employed as elec- 


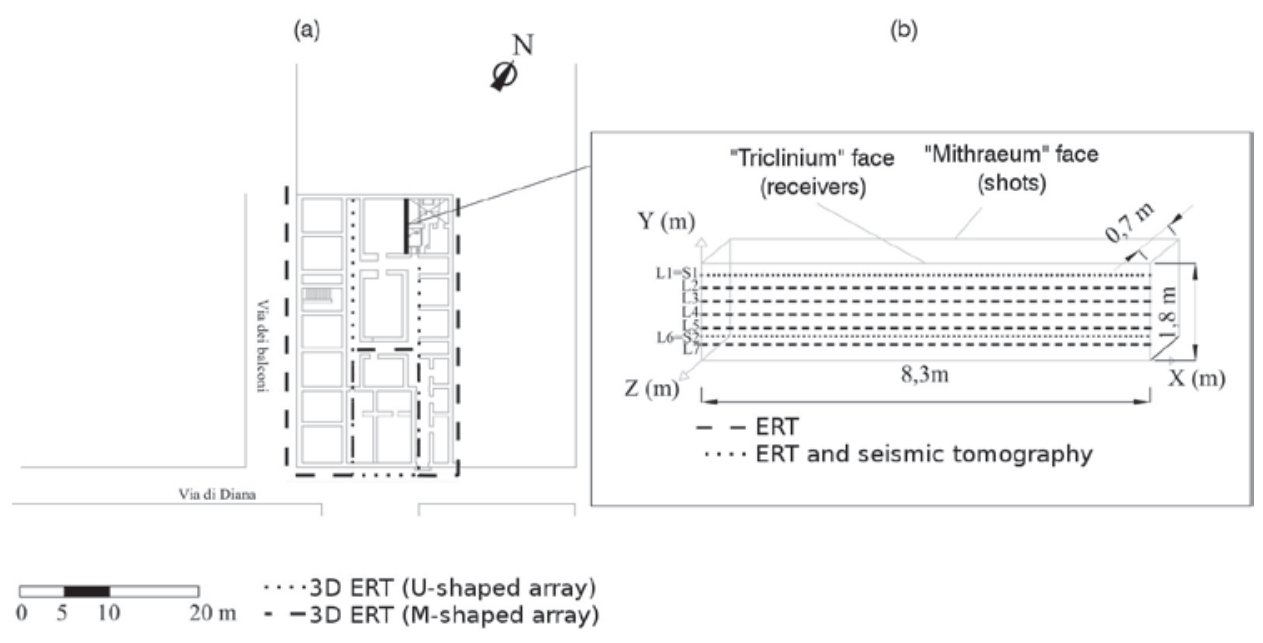

Figure 2 (a) Plan of 3D ERT investigation for detecting foundations (U shaped, dotted line; M shaped, dashed line). (b) Location of electrical (dashed and dotted) and seismic tomography (dotted) lines at the Triclinium wall.

(a)

Figure 3 (a) 3D ERT acquisition outside the building with stainless steel electrodes and (b) noninvasive copper plates as electrodes used alongside corridors. (c) ERT at the Triclinium wall using micro-electrodes connected with the Syscal Pro system. (d) Seismic tomography at the Triclinium wall with accelerometres connected with a 24-channel Geode seismograph.

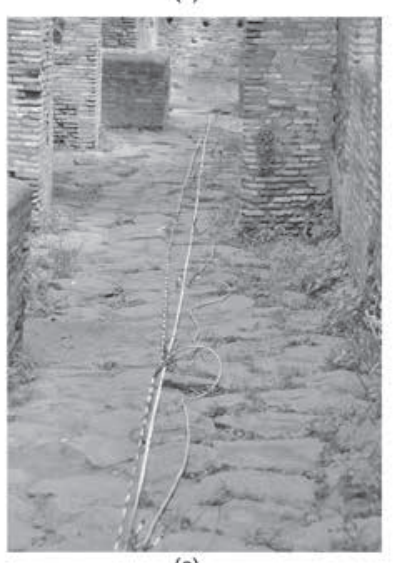

(c) (b)

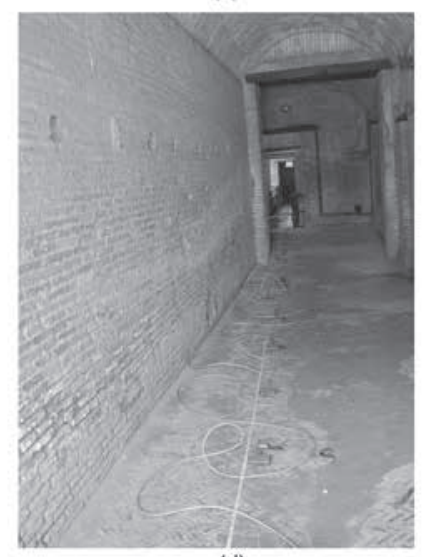

(d)

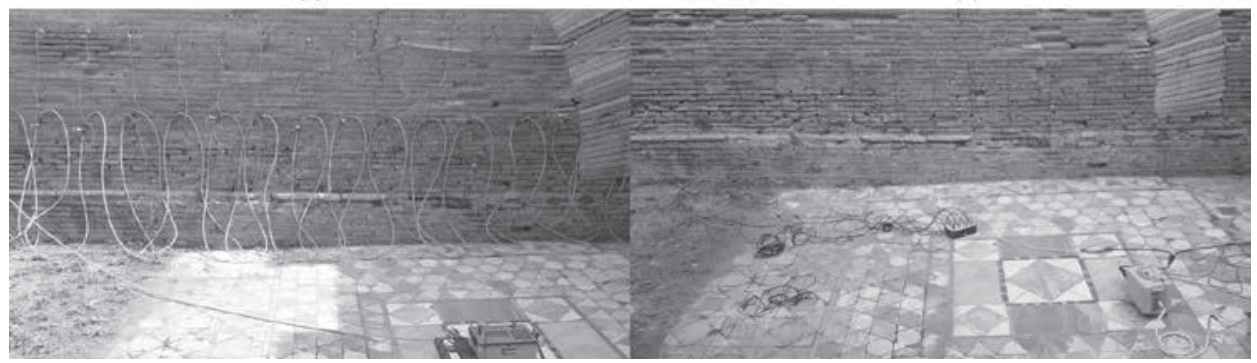

trodes outside and inside the building, respectively, with an electrode spacing of $3 \mathrm{~m}$.

ERT dataset were inverted with the Versatile interface for Electrical Modelling and Inversion (VEMI) algorithm (De Donno and Cardarelli 2017a), built within the Electrical Impedance tomography and Diffuse Optical tomography Reconstruction Software (EIDORS) environment (Adler and Lionheart 2006). This algorithm is able to perform both $2 \mathrm{D}$ and $3 \mathrm{D}$ inversions, by solving the forward problem with a finite-element approximation of the Laplace's equation governing the physical problem (De Donno and Cardarelli 2014) while inversion is carried out using a Gauss-Newton formulation (De Donno 2013). The code incorporates the electrode size (penetration depth for rods and plate length for surface electrodes) within the forward modelling, a non-negligible factor for archaeological applications. It is also possible to add a priori information to the inversion process. In this particular case, we made no preliminary assumption because of the few available information on the study area. Although the employed complex 3D configuration can lead to negative apparent resistivity values, the algorithm allows the user to delete the negative data or to retain the whole dataset, performing inversion with apparent resistivity and resistivity as data and model parameter, respectively, instead of the log-transformed quantity usually employed for ERT inversion. In the following section, we present the results achieved by the latter choice, where only the measurements with an observed standard deviation higher than $5 \%$ (about $2 \%$ of the whole dataset) were discarded. 


\section{"Triclinium" wall}

Electrical tomography profiles were acquired on the Triclinium wall at different heights (Figure 2b). ERT dataset consist of seven lines acquired at a height of 1.6, 1.35, 1.1, 0.85, 0.6, 0.45, and $0.3 \mathrm{~m}$ from the floor level (L1 to L7 in Figure 2b), using 24 steel micro-electrodes (steel nails having a length of $7 \mathrm{~cm}$ and a diametre of $0.25 \mathrm{~mm}$ ), spaced $0.35 \mathrm{~m}$ apart for each line, connected to the IRIS Syscal Pro (Figure 3c). Dipole-dipole and Wenner-Schlumberger arrays were combined (3283 data points) in order to merge the capability of resolving anomalies in the vertical (Wenner-Schlumberger) and horizontal (dipole-dipole) directions. Forward modelling and inversion was performed with VEMI replacing the Dirichlet boundary conditions, used for ground investigation, with a Neumann-type boundary condition due to the absence of current flow through the air-wall interface.

Two seismic profiles were collected at 1.6 and $0.45 \mathrm{~m}$ from the floor (S1 and S2 in Figure 2b, corresponding to L1 and L6), in order to validate the electrical models. Data were acquired using 11 shot points (spacing $=0.7 \mathrm{~m}$ ) operating with a $2-\mathrm{kg}$ hammer source and 23 piezoelectric accelerometres with a cutoff frequency of $4.5 \mathrm{kHz}$, spaced $0.35 \mathrm{~m}$ apart, while traces were recorded by means of a 24-channel geometrics Geode seismograph, with a sampling rate of $31.5 \mu$ s (Figure $3 \mathrm{~d}$ ). For each shot gather recorded for both seismic profiles, the first arrivals were manually picked and the travel times computed, as the difference between the shot instant and the first breaks of the P-wave. These data were inverted using the linear travel time interpolation method for ray tracing in the forward kernel (Cardarelli and Cerreto 2002) and the iterative biconjugate gradient algorithm for travel time inversion (Cardarelli and De Nardis 2001). The resolution of the inverted images was improved through the staggered grid technique (Cardarelli and Cerreto 2017), where inversion was computed seven times for each direction, starting from an initial cell size of $0.48 \mathrm{~m} \times 0.2 \mathrm{~m}$, leading to a final refined mesh of 2499 cells.

\section{Biological and environmental investigations}

The validation of geophysical results was performed by means of a study on the percentage coverage of the biological communities on the Triclinium wall. The analyses were carried out on the left part of the Mitraeum face of the Triclinium wall $(\mathrm{x}=4-8 \mathrm{~m}$ and $\mathrm{z}=$ $-0.7 \mathrm{~m}$ in Figure $2 \mathrm{~b}$ ), sheltered from the atmospheric agents, while it was unfeasible to investigate the right part of the wall due to the massive presence of podia. The calculation of the biological coverage has been executed with a new method that encompasses the combined use of the "stage" and the Braun-Blanquet rating scales.

The stage method (Scatigno and Ravera 2015) assigns different scores as a function of the actions needed to restore the investigated surface. This evaluation is done using a scalpel for testing the state of conservation of the wall. Then, the type of biological colonisation is found as a consequence of the conservation treatment (Table 1).

The Braun-Blanquet rating scale is a cover-abundance scale system (density method) that aims to distinguish homogeneous biological units, using the classification of plant communities made by the floristic school (Braun-Blanquet 1964). In the present work, the rating scores were attributed to a generalised biological presence and not to the single species, according to the original system. Therefore, the abundance was calculated as the percentage ratio between the area occupied by the biological species and the total area of the wall (Table 2).

The final scores were marked on a modular grid of $25 \mathrm{~cm} \times$ $25 \mathrm{~cm}$ according to the stage scale, whereas an overall score was attributed to the whole investigated surface using the modified Braun-Blanquet scale.

\section{Results}

\section{Foundation}

In Figure 4, we show the two meshes, used for forward (Figures $4 \mathrm{a}, \mathrm{b}$ ) and inverse (Figure 4c) computation. The VEMI algorithm is able to give a mapping between two meshes in order to assign the correct value of resistivity to the coarser mesh once the forward solution has been achieved and vice versa. This procedure is extremely important to save memory during inversion (we need to know resistivity only near the electrodes) without undermine the accuracy of the forward solver (we need to extend the external boundaries "far enough" from the current source).

Results from the 3D inversion on ground array are displayed in Figure 5 by means of horizontal sections drawn on the resistiv-

\begin{tabular}{|c|c|c|c|}
\hline Stage & $\begin{array}{l}\text { Conservation treatment for } \\
\text { biological colonisation }\end{array}$ & \multicolumn{2}{|c|}{ Biological colonisation type } \\
\hline 0 & Not needed & \multicolumn{2}{|c|}{-} \\
\hline 1 & $\begin{array}{l}\text { Superficial cleaning } \\
\text { (mechanical suction) }\end{array}$ & \multirow{4}{*}{$\begin{array}{l}\text { Mosses, } \\
\text { lichens and fungi }\end{array}$} & Shortly rooted \\
\hline 2 & $\begin{array}{l}\text { Deep cleaning (first chemical and } \\
\text { after mechanical) }\end{array}$ & & \multirow{3}{*}{ consolidated } \\
\hline 3 & Deep cleaning + consolidation & & \\
\hline 4 & $\begin{array}{c}\text { Deep cleaning }+ \text { consolidation due to } \\
\text { rupture }\end{array}$ & & \\
\hline 5 & $\begin{array}{l}\text { Deep cleaning }+ \text { consolidation due to } \\
\text { rupture by superior plants }\end{array}$ & \multicolumn{2}{|c|}{ Superior plants } \\
\hline
\end{tabular}

Table 1 Stage rating scale. 
(a)

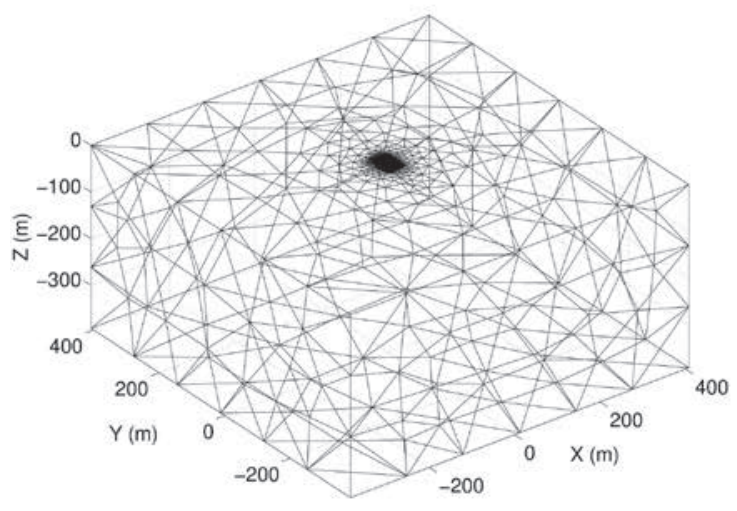

(b)

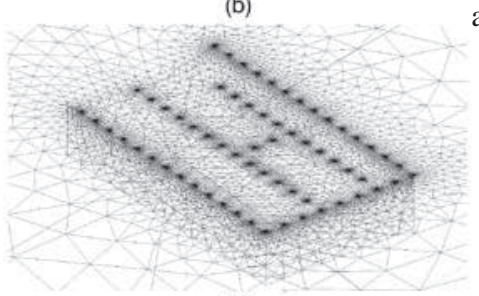

(c)

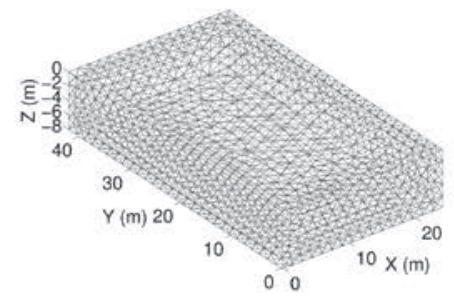

a Figure 4 3D ERT model of the Casa di Diana foundations. (a) Model for forward computation and (b) particular of the area within the black rectangle in Figure 1a, where the position of electrodes is highlighted. (c) Model for inversion. ity model at a depth of $1,2.5,4$, and $6 \mathrm{~m}$ from the floor level. The model highlights, in its shallower part (Figures 5a,b), three resistivity anomalies elongated in the y-direction, linked to the presence of buried walls acting as foundations. In fact, these bodies are located on the same vertical of the three load-bearing elements: two external walls and one intermediate spine wall. However, at major depths (Figures 5c,d), high resistivity values are visible only along the main external walls and can be interpreted as being due to the existence of foundations up to 5-7 m from the floor level. The background resistivity is about $30-50 \Omega \mathrm{m}$ up to a depth of $7 \mathrm{~m}$, compatible with the presence of a shallow aquifer. Similarly to the results previously obtained by Cardarelli et al. (2016b), below resistivity decreases abruptly to $1-2 \Omega \mathrm{m}$ as consequence of salt water intrusion.

However, since the resolution of ERT investigation rapidly decreases with depth, the deepest cells are often associated with the highest uncertainty. This effect can be evaluated by the analysis of the cumulative sensitivity $\mathbf{S}$, defined as follows (De Donno and Cardarelli 2017b):

$\mathrm{S}_{k}=\frac{\sum_{q=1}^{N_{Q}}\left|J_{q, k}\right|}{N_{Q}} ; k=1,2, \ldots, N_{E}$,

where $N_{E}$ is the number of elements, $N_{Q}$ is the number of measurements, and the absolute value of the Jacobian matrix $\mathbf{J}$ is given to avoid situations, where a negative sensitivity value for one measurement cancels out the positive value for another measurement. The cumulative sensitivity for this particular electrode configuration is shown in Figure 6, as horizontal slices cut at the same depths of ERT inverted model (1, 2.5, 4, and $6 \mathrm{~m}$ ). The sensitivity distribution is quite homogeneous in the shallow zones, demonstrating that this particular $3 \mathrm{D}$ array is able to enlighten about equally the investigated area, except for the northern zone $(\mathrm{y}>35 \mathrm{~m})$ where there is a lower measurement density. This resolution decrease is due to the operational constraints at the study site (inaccessibility of the northern part of the building). However, the sensitivity also decreases abruptly at depth of $5 \mathrm{~m}\left(S<10^{-4}\right)$. Therefore, the resistivity values of the deepest zones and of the northern part of the building, inferred from the speculative interpretation of the inverted model, may be not representative of the effective resistivity of the subsurface. In order to reduce this uncertainty, we set up a synthetic model (Figure 7), reproducing the layering early inferred from the interpretation of the inverted model of Figure 5. Results of inversion of synthetic data are represented in Figure 8, where horizontal slices are drawn at the same depth of the field example. Field and synthetic models (Figures 5 and 8) are comparable both in terms of shape and resistivity of the different bodies (pavement, foundation, freshwater-saltwater interface). A further comparison between field and synthetic models is made in Figure 9, where the resistivity values higher than $50 \Omega \mathrm{m}$ are associable to the presence of anthropic elements. There are no significant differences between the two models. Therefore, although few information about the hidden foundations are available, we can state that they consist of strip footings built underneath the two main loadbearing walls, as usually made for Roman buildings, even though their actual maximum depth is not inferable with a sufficient accuracy, using this particular electrode arrangement.

\section{Triclinium wall}

The 3D reconstruction of the Triclinium wall is shown in Figure 10 in terms of finite-element mesh (Figure 10a) and inverted resistivity model (Figure 10b). Owing to the particular

\begin{tabular}{ll}
\hline Rating & Percentage coverage [\%] \\
\hline 0 & Present, very scares cover \\
1 & Well represented, <5\% \\
2 & Abundant, $<25 \%$ \\
3 & $25-50 \%$ \\
4 & $50-75 \%$ \\
5 & $>75 \%$ \\
\hline
\end{tabular}

Table 2 Braun-Blanquet rating scale. 
boundary conditions discussed before, we used the same meshes for forward and inverse computations.

The inverted model is clearly divided into an upper resistive zone ( $\mathrm{h}>0.7 \mathrm{~m} ; \rho>500 \Omega \mathrm{m}$ ) and a conductive lower zone. This lower area is expected to be more conductive as a result of the effect of the rising damp, evident after a visual inspection. Among these layers, we can also identify another differentiation along the z-direction, directly correlated with the construction materials. In fact, the inner part of the wall is characterised by high resistivity values due to the high porosity of mortar, whereas its outer part appears to be slightly conductive, as consequence of the presence of bricks. Figure 11 enhances the layering of the Triclinium wall, by means of higher ( $>500 \Omega \mathrm{m}$, orange) and lower $(<500 \Omega \mathrm{m}$, blue) resistivity volumes. It is clearly visible that the conductive zone pertains to the portion of the wall affected by rising damp ( $\mathrm{h}<0.7 \mathrm{~m}$ ), whereas elsewhere, the resistivity is higher.

In Figure 12, the results coming from seismic inversion of the $\mathrm{S} 1$ (Figure 12a) and S2 (Figure 12b) profiles acquired on the wall (at the height of 1.6 and $0.45 \mathrm{~m}$ from the floor level) are presented in comparison with the respective slices extrapolated from the ERT model (Figures 12c,d). Both seismic models are characterised by low root mean square error (RMSE) values resulting from the last iteration ( 0.31 and $0.37 \mathrm{~ms}$, respectively).
There is a good correlation among the two sections in terms of shape and position of the reconstructed anomalies. Mainly, the low resistivity zones $(<500 \Omega \mathrm{m})$ correspond to high P-wave velocities $(>800 \mathrm{~m} / \mathrm{s})$, both located in the outer part of the wall, even though a high-resistivity and P-wave velocity area was found for the $\mathrm{S} 1$ (Figure 12a) at $\mathrm{x}=2 \mathrm{~m}$ and $\mathrm{z}=-0.6 \mathrm{~m}$, probably related to the presence of an arch. On the contrary, in the inner part of the section, low velocities $(<800 \mathrm{~m} / \mathrm{s})$ are associated to high resistivity values $(>500 \Omega \mathrm{m}$ ) due to the high porosity of the mortar. Therefore, geophysical models reflect the construction technique, where the outer brick layer is less porous and more rigid than the inner mortar. The detected lower velocities and high resistivity values could be due to the visible cracks and fractures on the wall.

\section{Biological and environmental analysis}

The biological studies confirm that conductive zones can be linked to rising damp and, consequently, to an increasing biological growth. The results of the biological analyses for the stage method are shown in Figure 13b, in comparison with the respective vertical section extrapolated from the 3D ERT model (Figure 13a).

The zone affected by biological proliferation is extended up to $0.75 \mathrm{~m}$ from the floor level, with the highest scores $(\geq 3)$ on (a)

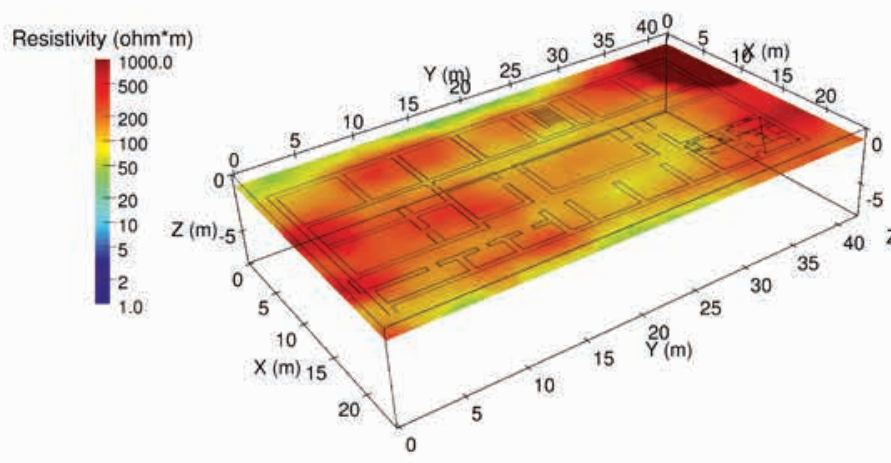

(c)

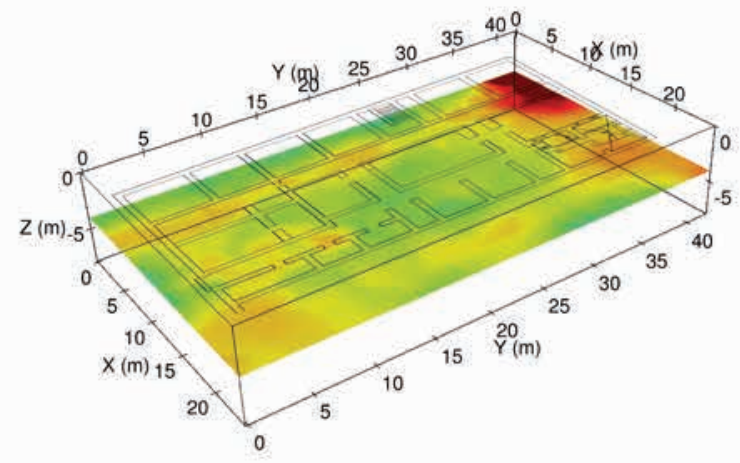

(b)

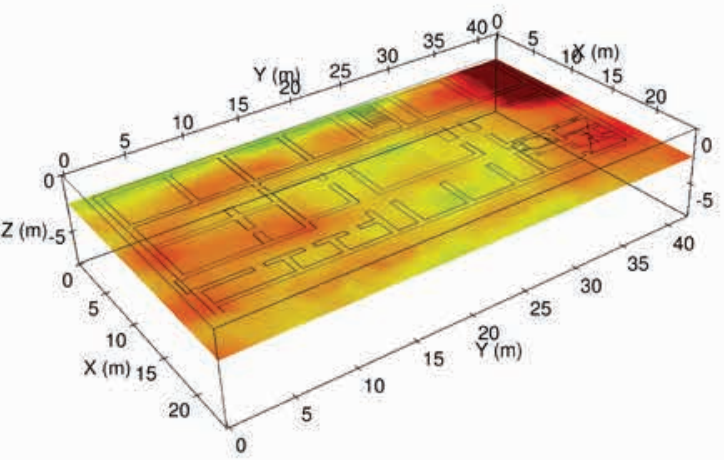

(d)

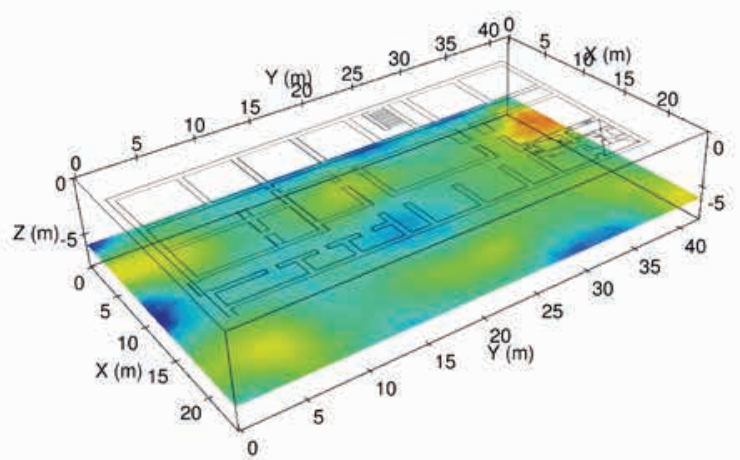

Figure 5 Inverted 3D ERT model of the Casa di Diana foundations. Horizontal sections are drawn at a depth of 1 (a), 2.5 (b), 4 (c), and 6 m (d) from the floor level. Images made using Kitware Paraview. 
(a)

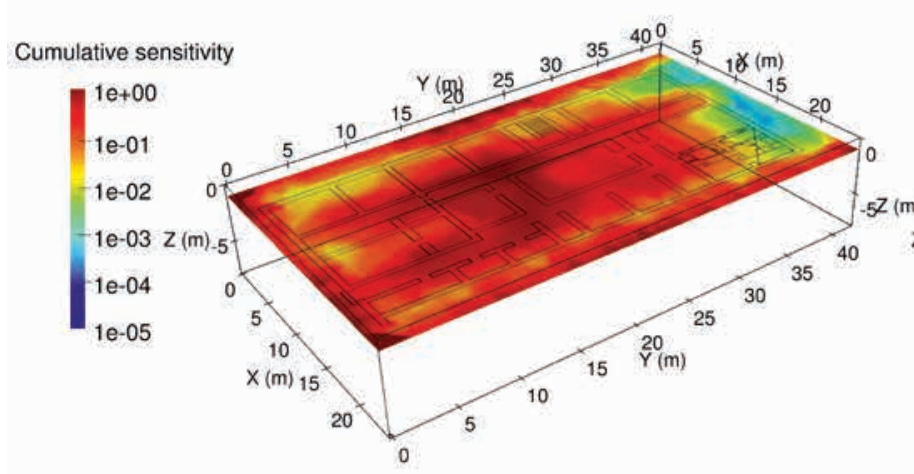

(c) (b)

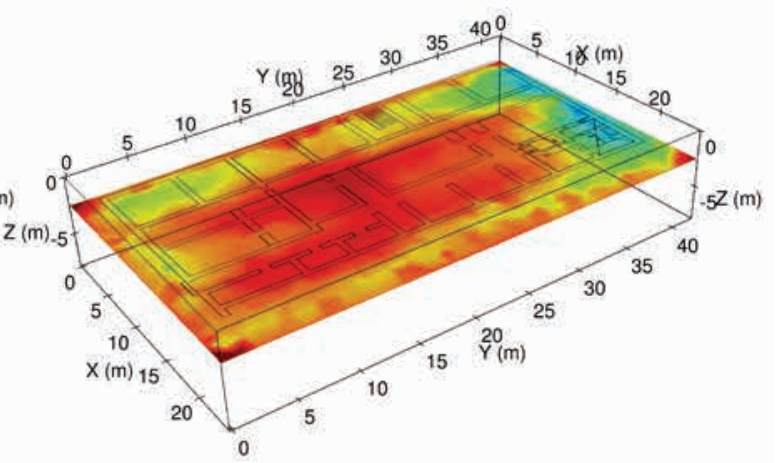

(d)
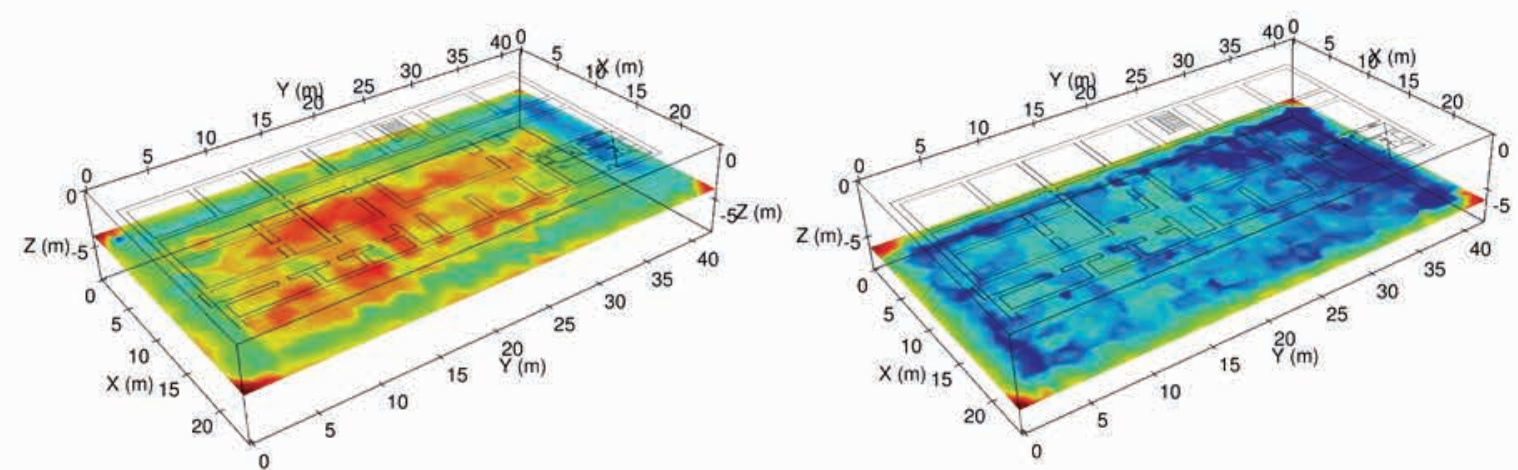

Figure 6 Cumulative sensitivity of the 3D ERT investigation. Horizontal sections are drawn at a depth of 1 (a), 2.5 (b), 4 (c), and $6 \mathrm{~m}$ (d) from the floor level. Images made using Kitware Paraview.

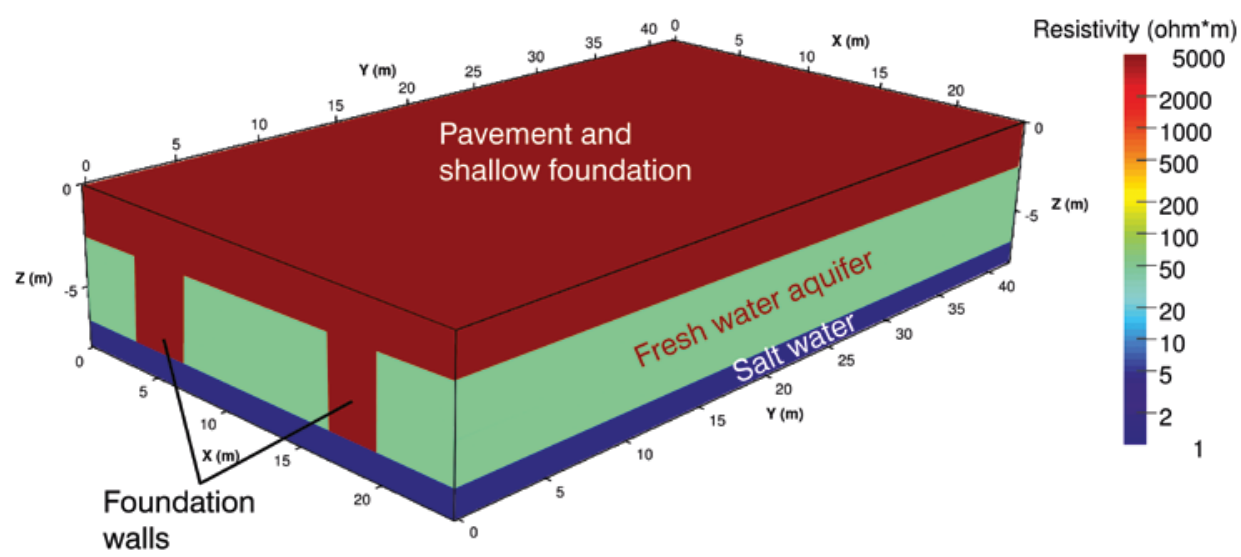

Figure 7 Synthetic 3D model of the Casa di Diana foundations.

the left bottom part of the wall (height of $0-0.5 \mathrm{~m}$ ) and the lowest $(\leq 1)$ in its right part, whereas the blank cells have a zero value. There is a good correspondence between the shape of biological and geophysical interfaces (dashed black lines in Figure 13). According to the Braun-Blanquet scale (Table 2), a mean coverage of $40 \%$ (score equal to 3 in Table 2) is assigned to the investigated wall.

In the lower strata of the wall (at the height of $0-0.75 \mathrm{~m}$ ), we also recorded low temperatures and relative humidity levels close to saturation, further confirming that rising damp is occurring at the Triclinium wall.

\section{DISCUSSION}

With reference to the five main points outlined in the Introduction, we merged together the results after Cardarelli et al. (2016b) (point (i)) and those relative to the foundations (point (ii)) in order to determine the resistivity range of natural and anthropogenic materials (point (iii)). Cardarelli et al. (2016b) established 
that the resistivity of the geological formations is lower than $50-60 \Omega \mathrm{m}$ and detected the fresh water/salt water interface at a depth of $8 \mathrm{~m}$ from the floor level (-5.5 $\mathrm{m}$ a.s.1.). Therefore, it is possible to deduce that resistivity values higher than $50 \Omega \mathrm{m}$ are caused by the existence of anthropogenic features (pavement, foundations), both in the ground and on the wall.

In addition, we can state that the building foundations may interact with the fresh water, since they are extended up to 5-7 m from the floor level, favouring the rising damp phenomenon on the investigated wall. These depths are not uncommon for Roman buildings, especially for those founded on low-/medium-stiff soils like silt and sand (Adam 2005; Cardarelli and Di Filippo 2009). In Roman architecture, footings are usually built with projections and a great variety of cross-sections, even though there was no rule for determining the size of the footings. The main need was to excavate the foundations until a solid bottom is to be found, and even to deepen further within it, as much as is necessary in relation to the importance of the construction. It cannot be excluded that foundations were deepen by driving stakes into the soil, a common practice for low stiff soils (Gamallo 2003).

However, the rapid decrease of sensitivity with depth, common for surface ERT array, prevents an accurate estimation of the maximum foundation depth, which can be over-estimated by metres, on the basis of the particular electrode configuration. In those cases, archaeological excavations, whereas feasible, could confirm the geophysical evidences.

Electrical and seismic models, reconstructed at the Triclinium wall, reveal to be strongly heterogeneous in the three main directions. Overall, we can associate high resistivity to low velocity values, both due to the high porosity of mortar. On the contrary, high velocities together with lower resistivities are linked to the more rigid and conductive brick layer. With reference to a previous work where a laboratory sample of a Roman masonry wall was analysed using seismic tomography (Cardarelli and De Nardis 1999), we can conclude that the bricks have velocity values compatible with a good state of conservation (optimal $\mathrm{V}_{\mathrm{P}}=1500-1700 \mathrm{~m} / \mathrm{s}$, recovered $\mathrm{V}_{\mathrm{P}}=1300-1500 \mathrm{~m} / \mathrm{s}$ ) in few zones, while there are many fractured areas where there is a substantial decrease of velocity. On the contrary, velocities calculated in the mortar (optimal $\mathrm{V}_{\mathrm{p}}=500 \mathrm{~m} / \mathrm{s}$, recovered $\mathrm{V}_{\mathrm{P}}=350-500 \mathrm{~m} / \mathrm{s}$ ) can potentially represent an anomaly due to degradation phenomena. In addition, the resistivity increase (and the velocity decrease) observed in the wall (in particular at $\mathrm{x}=1-2$ and $6-7 \mathrm{~m}$ and $\mathrm{y}=1-1.5 \mathrm{~m}$ ) and the conductive anomalous zone pointed out in Figure 8 could be due to cracking and rising damp phenomena, respectively.

In this sense, the chemical analyses described after Cardarelli et al. (2016b) validated the geophysical results. According to the (a)

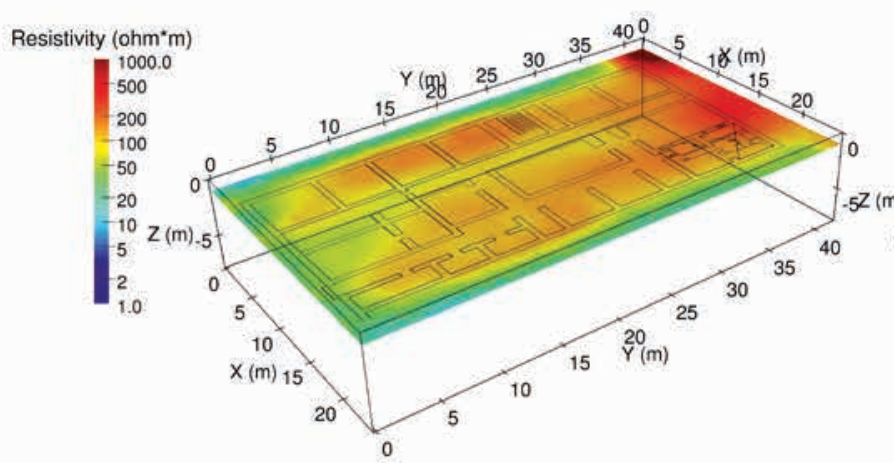

(c)

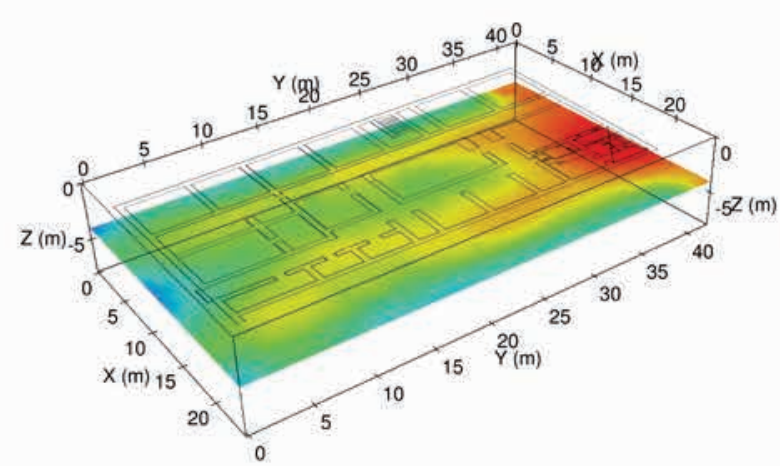

(b)

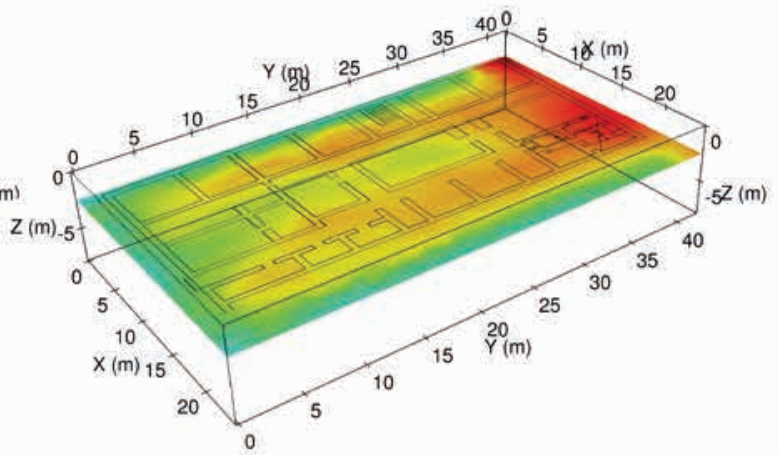

(d)

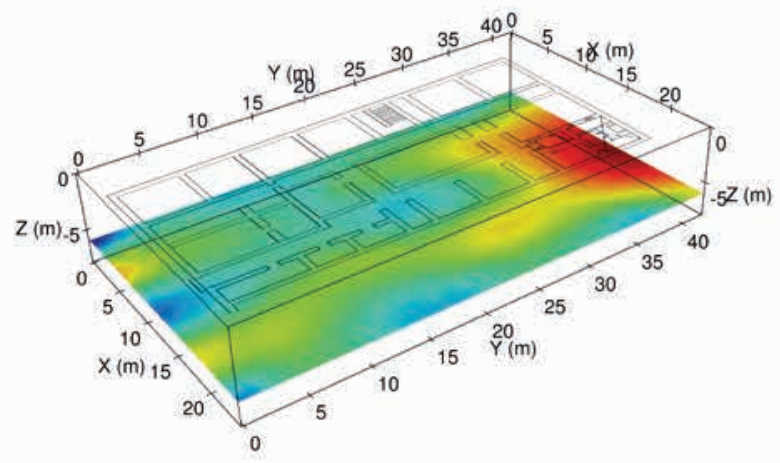

Figure 8 Inverted 3D ERT model of synthetic data of the Casa di Diana foundations. Horizontal sections are drawn at a depth of 1 (a), 2.5 (b), 4 (c), and $6 \mathrm{~m}$ (d) from the floor level. Images made using Kitware Paraview. 
authors, moisture from the rising damp makes the building's existing salts soluble. Then, this moisture evaporates on the wall's surface, leaving sulphate salt residue. For this, the geophysical surveys reveal a strong resistivity decrease in the lower zone of the wall. These conductive anomalies are also related to the existence of microbial communities, directly linked to the presence of water, pumped by these microorganisms from the shallow aquifer. In fact, the interface between conductive and resistive zones, detected by ERT surveys, is located at the same height (0.75) reached by the microbial communities (Figure 13).

On the basis of these results, we can state that an experimental procedure for investigating the structural elements should comprehend the reconstruction of a 3D model using extensively the electrical method, being rapid and cost-effective, both in terms of acquisition (30 minutes for each line) and data process- ing. However, the minimisation of the contact resistances of the electrodes is still a major issue because the use of completely non-invasive electrodes (plates or cylinders only lean against the wall) often not ensured a good electrical and/or mechanical contact due to the surface roughness and dryness of the archaeological structures.

Whereas the ambiguity in the model interpretation still remains, one can record seismic lines (more time consuming) on zones where uncertainty is higher. A preliminary quality factor can be given by the deviation between P-wave velocity and resistivity values measured in the field and the optimal values obtained in the laboratory, in order to identify the inner mortar and the outer brick component. Moreover, any anomalies due to degradation should be represented by a velocity decrease for the two materials.
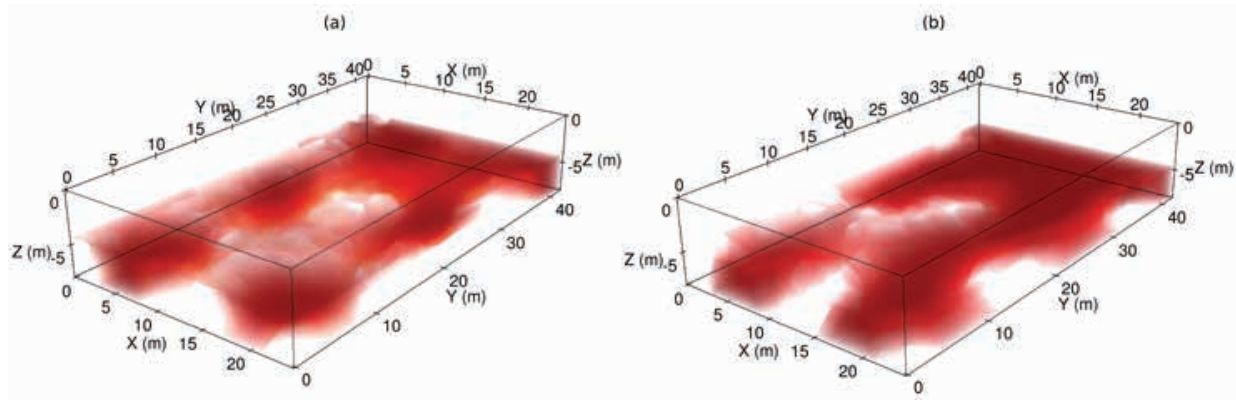

Figure 9 Volumetric image of the Casa di Diana foundation walls, obtained mapping only elements deeper than $4 \mathrm{~m}$ with resistivity values higher than $50 \Omega \mathrm{m}$. (a) Field data inversion. (b) Synthetic data inversion. Images made using Kitware Paraview.

Figure 10 3D ERT model of the Triclinium wall. (a) Mesh for forward and inverse computation. (b) Inverted model with horizontal slices drawn at 0.45 and $1.6 \mathrm{~m}$ from the floor level and vertical slice at a depth of $0.35 \mathrm{~m}$ from the outdoor face.
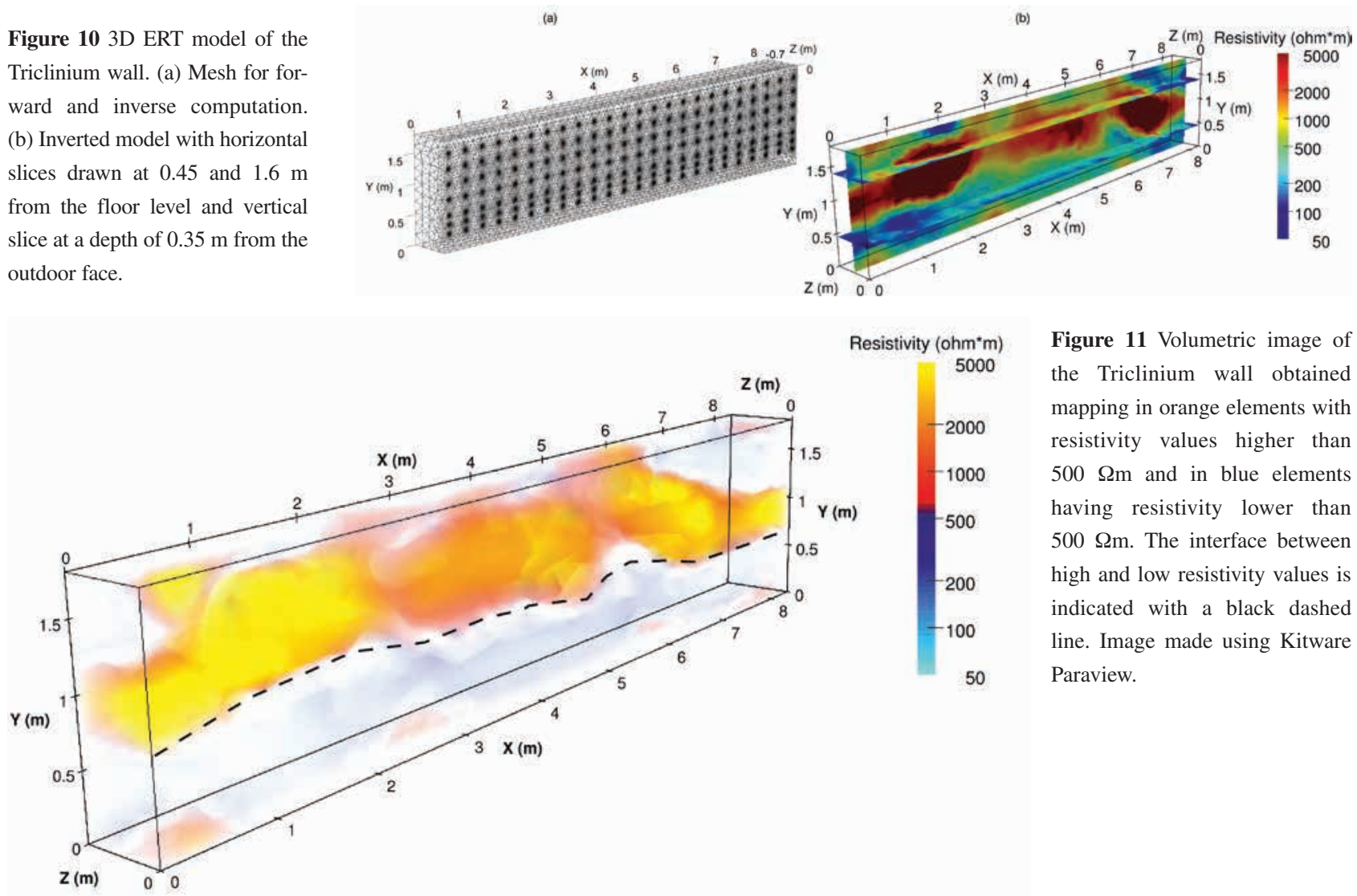

Figure 11 Volumetric image of the Triclinium wall obtained mapping in orange elements with resistivity values higher than $500 \Omega \mathrm{m}$ and in blue elements having resistivity lower than $500 \Omega \mathrm{m}$. The interface between high and low resistivity values is indicated with a black dashed line. Image made using Kitware Paraview. 


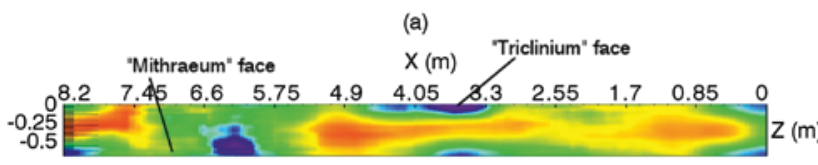

250500750100012501500

VP $(\mathrm{m} / \mathrm{s})$

(c)

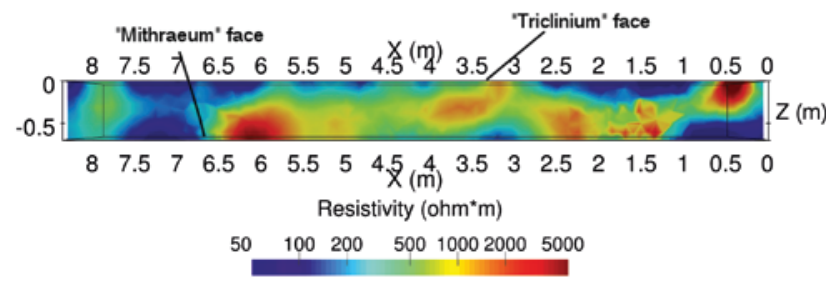

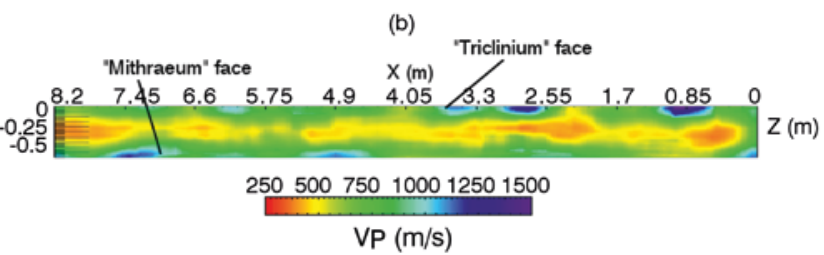

(d)

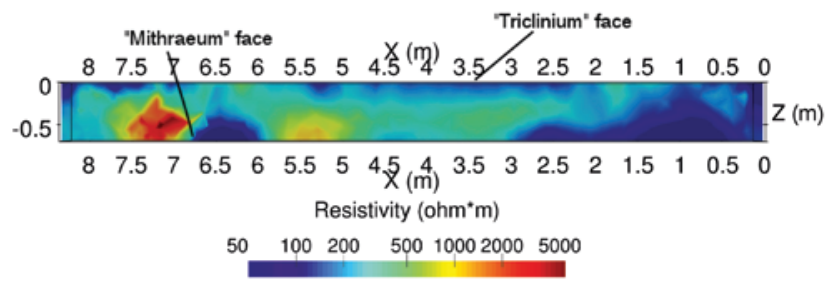

Figure 12 Inverted models of seismic profiles S1 (a) and S2 (b) at the Triclinium wall, compared with the respective slices of the 3D ERT model (c, d).

(a)

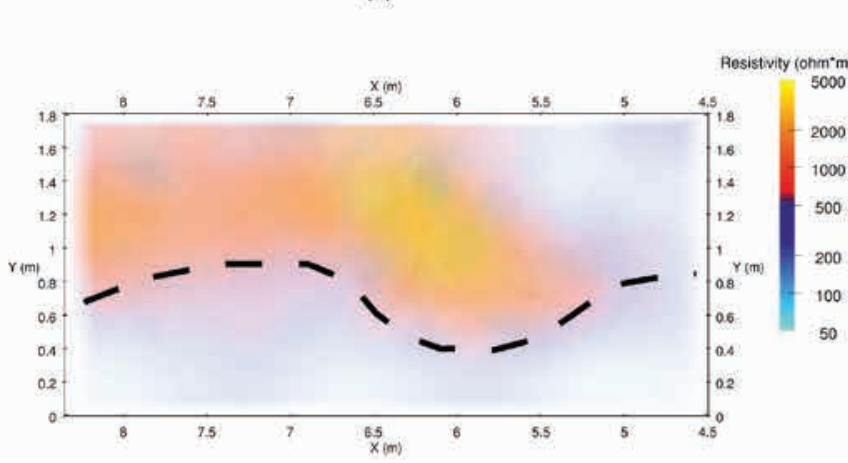

(b)

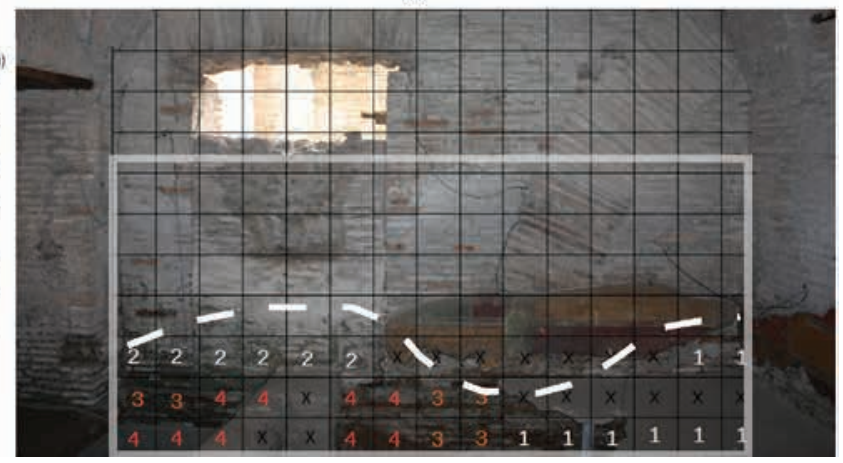

Figure 13 Comparison between geophysical model and biological analyses. (a) Vertical section of the 3D ERT model where the interface between high and low resistivity values is indicated with a black dashed line (b) Rating assigned with the stage method for biological proliferation on a 250 mm $\times$ $250 \mathrm{~mm}$ regular grid, where the location of ERT model is marked with black line and the interface between high and low resistivity values is superimposed.

However, if a residual uncertainty is still present on models reconstructed at point (iv), mainly regarding the causes of the conductive anomalies in the lower zone of the wall, biological analyses can help in this sense (point (v)).

\section{CONCLUSION}

An integrated experimental procedure is presented in this work for assessing the current state of conservation of a wall, prone to cracking and affected by rising damp.

Through a 3D ERT survey performed around the building, we could detect deep anomalous bodies acting as foundations. The recorded resistivity values higher than $50 \Omega \mathrm{m}$ can be related to anthropic features (pavement, foundations) because the resistivity range of the geological formations is lower. Foundations are probably strip footings located underneath the load bearing walls and extended up to a depth of 5-7 m, which can interact with the shallow aquifer, favouring the rising damp phenomenon on the elevated walls.

The combined use of electrical and seismic tomography, validated with biological analyses, can be a reliable tool to obtain a high-resolution model of a masonry wall, as demonstrated on the Triclinium wall made in opus caementicium. In fact, the revealed high electrical resistivity and low P-wave velocity values can be associated with the presence of the inner mortar, whereas the observed higher velocity and low resistivity values are probably due with the existence of the outer brick component. These background values change in the presence of degradation, due to cracking and rising damp. In the former case, we have an increase of resistivity in the bricks together with lower velocity values. The latter phenomenon affects the whole volume of the wall by means of a strong resistivity decrease. Overall, the wall is undergoing a noteworthy degradation process, proven by the massive presence of fractures (low velocity and high resistivity zones) and a significant volume where rising damp is present (low resistivity zone).

Validation of geophysical results has been given by biological studies. The presence of microorganisms, such as Cyanobacteria, green algae, and lichens, occurred mainly from the pavement up to $0.75 \mathrm{~m}$, which corresponds to the height where a sharp variation of resistivity was observed. In the left bottom part of the wall 
( $\mathrm{x}=5.5-8, \mathrm{y}=0-0.5 \mathrm{~m}$ ), where the stage rating is higher than 3 , very deep restoration actions are needed, such as cleansing and consolidation.

The described integrated method can be used to reconstruct a 3D model of a masonry structure: the interpretation of 3D ERT, integrated by seismic surveys and validated through biological analyses, can remove the ambiguity arising from interpretation of a single non-invasive technique. On the basis of these results, we make available to archaeologists a high-resolution tool useful to plan restoration activities at the study site.

Future works should explore the use of non-invasive methods for reducing the high relative humidity recorded at the archaeological site, a key parametre for the safeguard of this priceless historical building.

\section{ACKNOWLEDGEMENTS}

The core findings of this paper were presented at the 22nd EAGE-Near Surface Geoscience Meeting (Cardarelli et al. 2016a). The project was founded by "Sapienza" University of Rome-Ateneo Grant 2015 no. 267/D. Francesco Pugliese ("Sapienza" University of Rome) is thanked for his technical support on field survey. Claudia Scatigno is grateful to $\mathrm{PhD}$ Nagore Prieto-Taboada (University of the Basque Country UPV/EHU), for the grant for study sojourns by trainee researchers from foreign universities engaged in a jointly supervised doctoral thesis, and Sonia Ravena (University of Molise Department of biosciences and territory) for her contribution in the recognition of the biological species.

\section{REFERENCES}

Adam J.P. 2005. Roman Building: Materials and Techniques. London, UK: Routledge, Taylor \& Francis, 368 pp.

Adler A. and Lionheart W.R. 2006. Uses and abuses of EIDORS: an extensible software base for EIT. Physiological Measurement 27, S25.

Cardarelli E., Cercato M., De Donno G. and Di Filippo G. 2014. Detection and imaging of piping sinkholes by integrated geophysical methods. Near Surface Geophysics 12(3), 439-450.

Cardarelli E. and Cerreto A. 2017. Grid setting in seismic tomography for elliptical anisotropic media. Pure and Applied Geophysics 174(3), 1153-1165.

Cardarelli E and Cerreto A. 2002. Ray tracing in elliptical anisotropic media using linear travel-time seismic interpolation (LTI) method applied to travel time seismic tomography. Geophysical Prospecting 50, 55-72.

Cardarelli E., De Donno G., Oliveti I. and Scatigno C. 2016a. Assessing the state of conservation of a masonry building through the combined use of electrical and seismic tomography. 22nd European meeting of environmental and engineering geophysics, Barcelona, Spain, September 4-8.

Cardarelli E., De Donno G., Scatigno C., Oliveti I., Martinez M.P. and Prieto-Taboada N. 2016b. Geophysical and geochemical techniques to assess the origin of rising damp of a Roman building (Ostia Antica archaeological site). Microchemical Journal 129, 49-57.

Cardarelli E. and De Nardis R. 1999. The use of 3-D and 2-D seismic tomography for assessing the physical integrity of building panels. European Journal of Environmental and Engineering Geophysics 3, $131-142$.
Cardarelli E. and De Nardis R. 2001. Seismic refraction, isotropic anisotropic seismic tomography on an ancient monument (Antonino and Faustina temple AD 141). Geophysical Prospecting 49, 228-240.

Cardarelli E. and Di Filippo G. 2009. Integrated geophysical methods for the characterisation of an archaeological site (Massenzio BasilicaRoman forum, Rome, Italy). Journal of Applied Geophysics 68(4), 508-521.

Cataldo R., D'Agostino D. and Leucci G. 2012. Insight into the buried archaeological remains at the Duomo of Lecce (Italy) using ground penetrating radar surveys. Archaeological Prospection 19(3), 157165.

Clauss M. 2001. The Roman Cult of Mithras: the God and His Mysteries. Taylor \& Francis, Routledge, New York, 198 pp.

Conyers L.B. 2013. Ground-Penetrating Radar for Archaeology, 3rd edn. Latham, Maryland: Rowman and Littlefield Publishers, Alta Mira Press.

Creer S., Deiner K., Frey S., Porazinska D., Taberlet P., Thomas W.K. et al. 2016. The ecologist's field guide to sequence-based identification of biodiversity. Methods in Ecology and Evolution 7(9), 1008-1018

Crispim C.A. and Gaylarde C.C. 2005. Cyanobacteria and biodeterioration of cultural heritage: a review. Microbial Ecology 49(1), 1-9.

Daniels D.J. 2009. Ground Penetrating Radar, 2nd edn. London, UK: IET $734 \mathrm{pp}$.

D’Aranno P.J., De Donno G., Marsella M., Orlando L., Renzi B., Salviani S. et al. 2016. High-resolution geomatic and geophysical techniques integrated with chemical analyses for the characterization of a Roman wall. Journal of Cultural Heritage 17(1), 141-150.

De Donno G. 2013. 2D tomographic inversion of complex resistivity data on cylindrical models. Geophysical Prospecting 61(Suppl.1), 586601.

De Donno G. and Cardarelli E. 2014. 3D complex resistivity tomography on cylindrical models using EIDORS. Near Surface Geophysics 12(5), 587-598.

De Donno G. and Cardarelli E. 2017a. VEMI: a flexible interface for 3D tomographic inversion of time-and frequency-domain electrical data in EIDORS. Near Surface Geophysics 15(1), 43-58.

De Donno G. and Cardarelli E. 2017b. Tomographic inversion of timedomain resistivity and chargeability data for the investigation of landfills using a priori information. Waste Management 59, 302-315.

Franzoni E. 2014. Rising damp removal from historical masonries: a still open challenge. Construction and Building Materials 54, 123-136.

Gaffney C. 2008. Detecting trends in the prediction of the buried past: a review of geophysical techniques in archaeology. Archaeometry 50, 313-36.

Gamallo A.M.G. 2003. The evolution of traditional types of building foundation prior to the first industrial revolution. Proceedings of the First International Congress on Construction History, Madrid, Spain, January 20-24.

Gentilini C. Franzoni E., Bandini S. and Nobile L. 2012. Effect of salt crystallisation on the shear behaviour of masonry walls: an experimental study. Construction and Building Materials 37, 181-189.

Goodman D. and Piro S. 2013. GPR Remote Sensing in Archaeology. Berlin, Germany: Springer, 233 pp.

Green J.L., Bohannan B.J.M. and Whitaker R.J. 2008. Microbial biogeography: from taxonomy to traits. Science 320(5879), 1039-1043.

Merello Giménez P., Pérez García M.D.C., García Diego F.J., Fernández Navajas Á., Pérez Miralles J., Baró Zarzo J.L. et al. 2013. Ariadne's house (Pompeii, Italy) wall paintings: a multidisciplinary study of its present state focused on a future restoration and preventive conservation. Materiales de Construcción 63, 449-467.

Mikhalova M.V., Bellotti P., Valeri P. and Tortora P. 1999. Intrusion of seawater into the river part of the Tiber Month. Water Resources 26(6), 679-686. 
Mol L. and Preston P.R. 2010. The writing's in the wall: a review of new preliminary applications of electrical resistivity tomography within archaeology. Archaeometry 52, 1079-1095.

Mustafa K. 2013. Deterioration of different stones used in historical buildings within Nigde province, Cappadocia. Construction and Building Materials 48, 789-803.

Neubauer W., Eder-Hinterleitner A., Seren S. and Melichar P. 2002. Georadar in the Roman civil town Carnuntum, Austria: an approach for archaeological interpretation of GPR data. Archaeological Prospection 9(3), 135-156.

Orlando L., Cardarelli E., Cercato M. and De Donno G. 2015. Characterization of a pre-Trajan wall by integrated geophysical methods. Archaeological Prospection 22(3), 221-232.

Orlando L. and Slob E., 2009. Using multicomponent GPR to monitor cracks in a historical building. Journal of Applied Geophysics 67, 327-334.

Perez-Gracia V., Caselles J.O., Clapes J., Martinez G. and Osorio R. 2013. Non-destructive analysis in cultural heritage buildings: evaluating the Mallorca cathedral sup-porting structures. NDT \& $E$ International 59, 40-47.

Piro S., Goodman D. and Nishimura Y. 2003. The study and characterization of Emperor Traiano's villa (Altopiani di Arcinazzo, Roma) using high-resolution integrated geophysical surveys. Archaeological Prospection 10(1), 1-25.

Polymenakos L., Papamarinopoulos S., Miltiadou A. and Charkiolakis N. 2005. Investigation of the foundations of a Byzantine church by three-dimensional seismic tomography. Journal of Applied Geophysics $\mathbf{5 7}, 81-93$

Sass O. 2005. Rock moisture measurements: techniques, results, and implications for weathering. Earth Surf Process Landforms 30, 359374.
Scatigno C., Gaudenzi S., Sammartino M.P. and Visco G. 2016a. A microclimate study on hypogea environments of ancient roman building. The Science of the Total Environment, 566-567.

Scatigno C., Prieto-Taboada N., Martinez M.P., Conte A.M., GarcíaDiego F.J. and Madariaga J.M. 2016b. Analytical techniques for the characterisation of historical building materials: case study "Casa di Diana" Mithraeum (archeological site in Ostia Antica, Italy). In: Advances in Materials Science Research. Nova Science Publishers, Inc., New York.

Scatigno C. and Ravera S. 2015. Characterisation of the biological proliferation on Roman masonry case study: "Casa di Diana" Mithraeum (Ostia Antica, Rome - Italy). XXVIII Convegno Nazionale della Società Lichenologica Italiana in Lanciano (IT).

Singh D.P, Singh H.B. and Prabha R. 2016. Microbial Inoculants in Sustainable Agricultural Productivity, Vol. 1: Research Perspectives. Berlin, Germany: Springer.

Soupios P.M., Loupasakis C. and Vallianatos F. 2008. Reconstructing former urban environments by combining geophysical electrical methods and geotechnical investigations-An example from Chania, Greece. Journal of Geophysics and Engineering 5(2), 186.

Tsokas G.N., Diamanti N., Tsourlos P.I., Vargemezis G., Stampolidis A. and Raptis K.T. 2013. Geophysical prospection at the Hamza Bey (Alkazar) monument Thessaloniki, Greece. Mediterranean Archaeology and Archaeometry 13, 9-20.

Tsourlos P.I. and Tsokas G.N. 2011. Non-destructive electrical resistivity tomography survey at the south walls of the Acropolis of Athens. Archaeological Prospection 18(3), 173-186.

Westley K., Plets R. and Quinn R. 2014. Holocene paleo-geographic reconstructions of the Ramore Head Area, Northern Ireland, using geophysical and geotechnical data: paleo-landscape mapping and archaeological implications. Geoarchaeology 29(6), 411-430. 